\title{
Conditional Rhythmicity of Ventral Spinal Interneurons Defined by Expression of the Hb9 Homeodomain Protein
}

\author{
Jennifer M. Wilson, ${ }^{1}$ Robert Hartley, ${ }^{3}$ David J. Maxwell, ${ }^{3}$ Andrew J. Todd, ${ }^{3}$ Ivo Lieberam, ${ }^{4}$ Julia A. Kaltschmidt, ${ }^{4}$ \\ Yutaka Yoshida, ${ }^{4}$ Thomas M. Jessell, ${ }^{4}$ and Robert M. Brownstone ${ }^{1,2}$ \\ Departments of ${ }^{1}$ Anatomy and Neurobiology and ${ }^{2}$ Surgery (Neurosurgery), Dalhousie University, Halifax, Nova Scotia, Canada B3H 1X5, ${ }^{3}$ Institute of \\ Biomedical and Life Sciences, University of Glasgow, Glasgow G12 8QQ, United Kingdom, and ${ }^{4}$ Howard Hughes Medical Institute, Center for Neurobiology \\ and Behavior, Columbia University, New York, New York 10032
}

The properties of mammalian spinal interneurons that underlie rhythmic locomotor networks remain poorly described. Using postnatal transgenic mice in which expression of green fluorescent protein is driven by the promoter for the homeodomain transcription factor $\mathrm{Hb}$, as well as $\mathrm{Hb}$ 9-lacZ knock-in mice, we describe a novel population of glutamatergic interneurons located adjacent to the ventral commissure from cervical to midlumbar spinal cord levels. $\mathrm{Hb}^{+}{ }^{+}$interneurons exhibit strong postinhibitory rebound and demonstrate pronounced membrane potential oscillations in response to chemical stimuli that induce locomotor activity. These data provide a molecular and physiological delineation of a small population of ventral spinal interneurons that exhibit homogeneous electrophysiological features, the properties of which suggest that they are candidate locomotor rhythm-generating interneurons.

Key words: locomotion; central pattern generator; transcription factors; conditional bursting; postinhibitory rebound; rhythm generation

\section{Introduction}

The mammalian spinal cord contains a complex network of local circuit interneurons that are involved in generating locomotor output in the absence of descending and afferent input (Brown, 1911). Pioneering in vivo experiments in the cat have led to the classification of spinal ventral interneurons by their location, segmental input, and axonal projections (Jankowska, 1992). Certain ventral interneuron populations are rhythmically active during locomotor activity (Baev et al., 1979; Gossard et al., 1994; Huang et al., 2000; Nakayama et al., 2002; Butt and Kiehn, 2003; Matsuyama et al., 2004). However, the intrinsic properties, which likely play a key role in rhythm generation (Getting, 1989), have seldom been studied in defined interneuronal populations (Butt et al., 2002).

The spinal interneurons responsible for mammalian locomotor rhythm generation remain poorly defined. Molecular studies have provided evidence that ventral interneuron subtypes derive from distinct progenitor domains (Ericson et al., 1997; Pierani et al., 1999). At early stages of spinal cord development, motoneu-

\footnotetext{
Received Jan. 19, 2005; revised May 4, 2005; accepted May 6, 2005.

This work was supported by operating grants from the Human Frontier Science Program (T.M.J., D.J.M., A.J.T., R.M.B.) and The Wellcome Trust (D.J.M., A.J.T.). T.M.J. is an investigator and Y.Y. is a research associate of the Howard Hughes Medical Institute. J.M.W. and R.M.B. are affiliated with the Dalhousie University Brain Repair Centre We thank Dr. Silvia Arber for the generous gift of the anti-Hb9 antibody, Drs. Larry Jordan and Gareth Miles for their comments on this manuscript, and Dr. Frank Smith for his technical input. We are grateful to Haiyun Zhang, Heather Kearns, and Adrian Mendez for their technical assistance.

Correspondence should be addressed to Robert M. Brownstone, Department of Anatomy and Neurobiology, 14A Sir Charles Tupper Medical Building, 5850 College Street, Halifax, Nova Scotia, Canada B3H 1X5. E-mail: rob.brownstone@dal.ca.

DOI:10.1523/JNEUROSCI.0274-05.2005

Copyright $\odot 2005$ Society for Neuroscience $\quad$ 0270-6474/05/255710-10\$15.00/0
}

rons and four major subclasses of ventral interneurons (V0-V3) are generated (Briscoe et al., 2000). Their distinct identities are determined by the profile of transcription factors expressed, both in progenitor cells and postmitotic neurons (Goulding and Lamar, 2000; Jessell, 2000). Although interneurons derived from each major progenitor domain share common functional features, it is likely that, given the anatomical and physiological diversity of adult spinal interneurons, each of these classes can be subdivided into a number of distinct functional populations (Goulding et al., 2002). Identification of physiologically coherent populations of neurons may therefore depend on the availability of additional molecular markers that are expressed in the postnatal period, when the nascent circuitry of the ventral spinal cord acquires characteristics of the mature locomotor network.

A homeodomain transcription factor, $\mathrm{Hb} 9$, is expressed by embryonic motoneurons and functions during development to consolidate motoneuron identity (Arber et al., 1999; Thaler et al., 1999). Like many other transcription factors involved in the specification of neuronal identity, $\mathrm{Hb} 9$ is evolutionarily conserved, and its Drosophila counterpart also functions during motoneuron differentiation (Odden et al., 2002). In Drosophila, Hb9 expression also defines specific interneuron classes (Broihier and Skeath, 2002; Odden et al., 2002), raising the possibility that expression of the protein in vertebrate interneurons may have been overlooked. In this study, we used Hb9:enhanced green fluorescent protein (eGFP) (Wichterle et al., 2002) and Hb9 ${ }^{\text {nlsLacZ }}$ (Arber et al., 1999) transgenic mice to define and characterize a population of small $\mathrm{Hb}^{+}{ }^{+}$interneurons abutting the ventral commissure (Wilson et al., 2003; Wilson and Brownstone, 2004). These $\mathrm{Hb}{ }^{+}$interneurons are glutamatergic, have homogeneous electrophysiological properties, and oscillate conditionally in re- 
sponse to drugs that induce locomotor activity. These data provide evidence for the existence of a small population of ventral spinal interneurons that are candidate rhythm-generating interneurons. A recent study (Hinckley et al., 2005) used the same eGFP transgenic mouse line and demonstrated rhythmically active $\mathrm{GFP}^{+}$neurons during induced ventral root bursting in the newborn spinal cord. Our studies expand on these findings by detailing the properties of a homogeneous population of endogenous $\mathrm{Hb} 9$ interneurons in motor functionally mature mice.

\section{Materials and Methods}

Generation of Hb9 transgenic mice. Hb9:eGFP transgenic mice ( $m$ HB9$G f p 1 b$ ) were generated by pronuclear injection of an $\sim 9 \mathrm{~kb}$ fragment comprising the $5^{\prime}$ upstream region of the murine HB9 gene (Arber et al., 1999), followed by a $5^{\prime}$ splice substrate (Choi et al., 1991), an eGFP gene, and a bovine growth hormone polyadenylation signal (Wichterle et al., 2002), and carry an estimated 5-10 copies of the transgene. These mice were of the same line we provided to Hinckley et al. (2005). Hb $9^{\text {nlsLacZ/+ }}$ mice were generated by homologous recombination in embryonic stem cells and carry a nuclear localized LacZ insertion in the Hb9 locus (Arber et al., 1999). Mice expressing both nlsLacZ and GFP were generated by intercrossing the Hb9:eGFP transgene line with heterozygous $\mathrm{Hb} 9^{\text {nlsLacZ/+ }}$ mice.

In situ hybridization and immunohistochemistry. Combined fluorescent in situ hybridization histochemistry/immunohistochemistry was performed as described by Vosshall et al. (2000) and Price et al. (2002), but proteinase $\mathrm{K}$ treatment was omitted. Antisense digoxigenin (DIG) riboprobe for vesicular glutamate transporter 2 (VGLUT2) was generated according to the recommendations of the manufacturer (Roche Diagnostics, Indianapolis, IN). Rabbit anti-GFP primary antibody (Molecular Probes, Eugene, OR) was applied together with sheep anti-DIGperoxidase (Roche Diagnostics), washed with $0.1 \mathrm{M}$ Tris $7.5,0.15 \mathrm{M} \mathrm{NaCl}$, and $0.05 \%$ Tween 20 , and detected using donkey anti-rabbit FITC secondary antibody (Jackson ImmunoResearch, West Grove, PA) and tyramide-cyanine 3 (Cy3) amplification (PerkinElmer, Boston, MA). Slides were mounted in Vectashield reagent (Vector Laboratories, Burlingame, CA), and images were collected using a Bio-Rad (Hercules, CA) MRC1024 scan head on a Nikon (Tokyo, Japan) E800 microscope.

For the immunohistochemical experiments, mice were perfused with $4 \%$ paraformaldehyde, and their spinal cords were removed, postfixed, and subsequently cryoprotected overnight in $30 \%$ sucrose. Cryostat or freezing microtome sections $(20-70 \mu \mathrm{m})$ were incubated free floating at $4^{\circ} \mathrm{C}$ for $24-72 \mathrm{~h}$ with combinations of the following primary antibodies diluted in PBS containing $0.3 \mathrm{M} \mathrm{NaCl}$ and $0.3 \%$ Triton X-100: rabbit (1:4000; Abcam, Cambridge, UK), chicken (1:2500), or sheep (1:1000) anti-GFP (Biogenesis, Poole, UK); rabbit anti-Hb9 (1:16,000; a gift from S. Arber, Biozentrum, University of Basel, Basel, Switzerland); rabbit anti- $\beta$-galactosidase ( $\beta$-gal) (1:1000; Biogenesis); goat anti-Fos (1:1000), anti-choline acetyltransferase (ChAT) (1:100), guinea pig anti-VGLUT2 (1:5000), anti-VGLUT1 (1:20,000), anti-glycine transporter 2 (GlyT2) $(1: 10,000)$, and rabbit (1:5000) and mouse (1:5000) anti-GAD-67 (all from Chemicon, Temecula, CA; Chandlers Ford, UK); rabbit anti-GlyT2 (1:2500; Sigma, St. Louis, MO); or goat anti-5-HT (1:5000; ImmunoStar, Hudson, WI). Sections were rinsed three times for $10 \mathrm{~min}$ each in PBS containing $0.3 \mathrm{M} \mathrm{NaCl}$ before incubation with secondary antibodies at $4^{\circ} \mathrm{C}$ overnight (Todd et al., 2003; Hughes et al., 2004). Appropriate secondary antibodies were conjugated to Alexa 488, Alexa 555, Cy3 or Alexa 637 (1:500; Molecular Probes), or rhodamine or Cy5 (1:100; Jackson ImmunoResearch). Fluorogold (1\%; Fluorochrome, Denver, CO) was injected intraperitoneally into mice $2-5 \mathrm{~d}$ before perfusion (Leong and Ling, 1990).

Image acquisition. Epifluorescent images were acquired with a Zeiss (Oberkochen, Germany) Axoplan inverted microscope, and confocal images were acquired with a Zeiss Axiovert 100M or a Bio-Rad Radiance 2100 confocal laser-scanning microscope equipped with argon, $\mathrm{HeNe}$, and red diode lasers, through $25-100 \times$ oil-immersion objectives. Images were processed using MetaMorph (Universal Imaging, Marlow, UK), and figures were made with Adobe Photoshop (Adobe Systems, San Jose, CA).

Electrophysiological recordings. All procedures are in accordance with

\section{GFP}
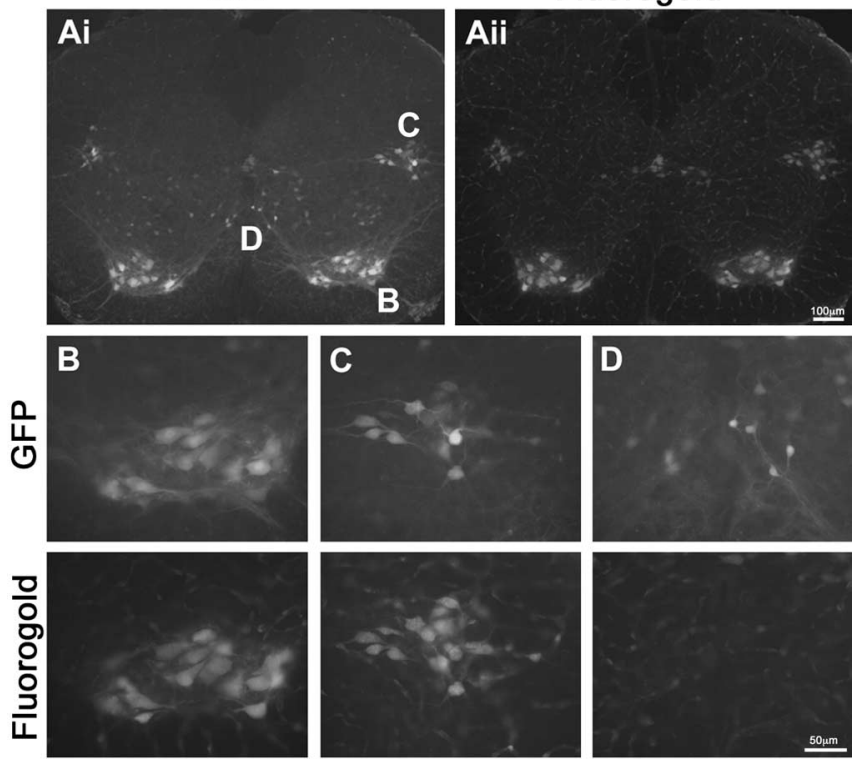

Figure 1. $\mathrm{GFP}^{+}$motoneurons and interneurons in the spinal cord of the postnatal $\mathrm{Hb}$ 9:GFP mouse. $\boldsymbol{A}$, Fluorescent micrographs of $30 \mu \mathrm{m}$ upper lumbar spinal cord sections illustrate GFPexpressing neurons in the ventral spinal cord $(\boldsymbol{A} \boldsymbol{i})$, which include somatic and sympathetic motoneurons, identified by colocalization with Fluorogold (Aii). Note the labeling of sympathetic preganglionic neurons in the intermediolateral cell column and central autonomic area, dorsal to the central canal. $\boldsymbol{B}-\boldsymbol{D}$, High-magnification images corresponding to marked regions in $\boldsymbol{A}$ illustrate somatic $(\boldsymbol{B})$ and sympathetic preganglionic ( $\boldsymbol{C}$ ) motoneuron GFP expression, identified by Fluorogold labeling. $\boldsymbol{D}, \mathrm{GFP}^{+}$neurons that abut the ventral commissure are not Fluorogold positive and are therefore interneurons.

protocols approved by and conforming to the Canadian Council for Animal Care and the Dalhousie University Animal Care Committee. Postnatal Hb9:GFP mice [postnatal day 6 (P6) to P14] were anesthetized with ketamine $(100 \mathrm{mg} / \mathrm{kg}$, i.p.), and their spinal cords were isolated and removed under cold $\left(<4^{\circ} \mathrm{C}\right)$ sucrose-substituted artificial CSF (ACSF) [detailed by Jiang et al. (1999)]. Transverse spinal cord slices (200-300 $\mu \mathrm{m}$ ) prepared with a vibrating microtome (Vibratome 3000; Vibratome, St. Louis, MO) were transferred to warm $\mathrm{ACSF}$ at $30^{\circ} \mathrm{C}$ for $15 \mathrm{~min}$ before a 30 min equilibration period in room-temperature ACSF before recording (Carlin et al., 2000). ACSF containing (in mM) $127 \mathrm{NaCl}, 1.9 \mathrm{KCl}, 1.2$ $\mathrm{KH}_{2} \mathrm{PO}_{4}, 2.4 \mathrm{CaCl}_{2}, 1.3 \mathrm{MgCl}_{2}, 26 \mathrm{NaHCO}_{3}$, and $10 \mathrm{D}$-glucose was superfused. Patch-clamp electrodes (5-9 M $\Omega$ ) contained $130 \mathrm{~mm}$ K-gluconate, $10 \mathrm{~mm} \mathrm{KCl}, 10 \mathrm{~mm}$ HEPES, 0.1 mM EGTA, 1 mM CaCl , 4 mM $\mathrm{Mg}-\mathrm{ATP}$, and $70 \mu \mathrm{M}$ Alexa 594. $\mathrm{GFP}^{+}$neurons were identified under fluorescence using a narrow-band GFP filter (41020; Chroma Technology, Rockingham, VT), and whole-cell patch-clamp recordings were obtained using differential interference contrast optics under infrared illumination and a MultiClamp 700A amplifier, Digidata 1322A analog-to-digital converter, and AxoGraph 4.9 software (Molecular Devices, Union City, CA). All drugs (0.1-1 mM NiCl $2,20 \mu \mathrm{M}$ 5-HT, $50 \mu \mathrm{M}$ dopamine, 5-20 $\mu \mathrm{M}$ NMDA, and $1 \mu \mathrm{M}$ TTX) were applied to the perfusate.

\section{Results}

\section{The identity of GFP-expressing neurons}

In the mammalian spinal cord, the homeobox gene $\mathrm{Hb} 9$ is expressed by embryonic motoneurons (Pfaff et al., 1996; Saha et al., 1997; Tanabe et al., 1998; Thaler et al., 1999). Its encoded homeodomain protein, $\mathrm{Hb} 9$, has an essential role in consolidating motoneuron fate (Arber et al., 1999; Thaler et al., 1999).

To investigate the postnatal expression of $\mathrm{Hb} 9$ in the mouse, GFP was expressed under the control of an $\sim 9 \mathrm{~kb} 5^{\prime}$ flank regulatory region (Wichterle et al., 2002). At postnatal stages, GFP was expressed by many motoneurons in the ventral spinal cord (Fig. 1). In P10 to adult mice, $\mathrm{GFP}^{+}$somatic motoneurons were 
observed in lateral and medial motoneuron pools in the ventral horns throughout the spinal cord (Fig. 1A,B). To examine whether all motoneurons express GFP, motoneurons were labeled by intraperitoneal injection of Fluorogold, which is taken up by peripheral axons to retrogradely label motoneuronal somata (Leong and Ling, 1990). In one representative animal in which the T12-L2 segments were analyzed, $\sim 85 \%$ (547 of 641 ) of Fluorogold-positive motoneurons were $\mathrm{GFP}^{+}$. Fluorogold also labeled $\mathrm{GFP}^{+}$ sympathetic preganglionic neurons (SPNs) (Fig. 1 A,C) (243 of 313; 78\% between T12-L2). Thus, not all somatic motoneurons or SPNs express GFP at postnatal ages.

We observed that interneurons in Hb9: eGFP mice, defined by the lack of Fluorogold tracer, also expressed GFP. These $\mathrm{GFP}^{+}$interneurons were located throughout the ventral horn, primarily in laminas VII, VIII, and ventral X (Fig. $1 A, D$ ). In the low thoracic to upper lumbar regions, an average of $41 \pm 5 \mathrm{GFP}^{+}$interneurons per $30 \mu \mathrm{m}$ section were observed in laminas VII and VIII and in ventral lamina X. Of note were small $(8-10 \mu \mathrm{m}$ diameter) interneurons ( $4 \pm 2$ of these interneurons per $30 \mu \mathrm{m}$ section) that abutted the ventral commissure in medial lamina VIII or ventral lamina $\mathrm{X}$ and often formed discrete clusters comprising two or three interneurons (Fig. $1 A, D$ ). Because the majority of these cells were in medial lamina VIII, we will refer to them as such. The intensity of GFP fluorescence in these neurons appeared greater than that seen in the majority of other labeled interneurons.

Previous studies using the $\mathrm{Hb} 9$ promoter have reported ectopic GFP expression in embryonic interneurons (Wichterle et al., 2002). To investigate the correspondence of transgene GFP expression with endogenous $\mathrm{Hb} 9$ expression in interneurons, Hb9:eGFP mice were crossed with Hb9 ${ }^{\text {nlsLacZ/+ }}$ mice (Arber et al., 1999). In the double-transgenic offspring, $\beta$-gal expression was detected in the nuclei of large $\mathrm{GFP}^{+}$motoneurons in the ventral horn (Fig. $2 A, D)$ and in the cluster of small $\mathrm{GFP}^{+}$cells abutting the ventral commissure (Fig. $2 B$ ). Importantly, the $\mathrm{GFP}^{+}$interneurons scattered throughout the remainder of the ventral horn lacked $\beta$-gal expression (Fig. $2 C$ ). Somatic motoneurons and the medially located cluster of $\mathrm{GFP}^{+}$interneurons expressed $\mathrm{Hb} 9$ immunoreactivity (data not shown). In contrast, $\mathrm{GFP}^{+}$interneurons scattered throughout lamina VII and VIII lacked endogenous Hb9 protein expression. Thus, medial lamina VIII eGFP ${ }^{+}$ interneurons alone correspond to endogenous $\mathrm{Hb}^{+}$ interneurons.

The rostrocaudal distribution of $\beta$-gal ${ }^{+}, \mathrm{GFP}^{+}$interneurons was investigated in the spinal cord of P10 to adult Hb9:eGFP $\times$ Hb9 ${ }^{\text {nlsLacZ/+ }}$ double-transgenic mice. At thoracic levels, occasional $\mathrm{Hb}^{+}{ }^{+}$neurons were observed in lamina $\mathrm{X}$, below the central canal abutting the ventral commissure, whereas at upper lumbar levels, these neurons were found in more ventral locations, forming clusters along the commissure (mean, 2.2 per 30
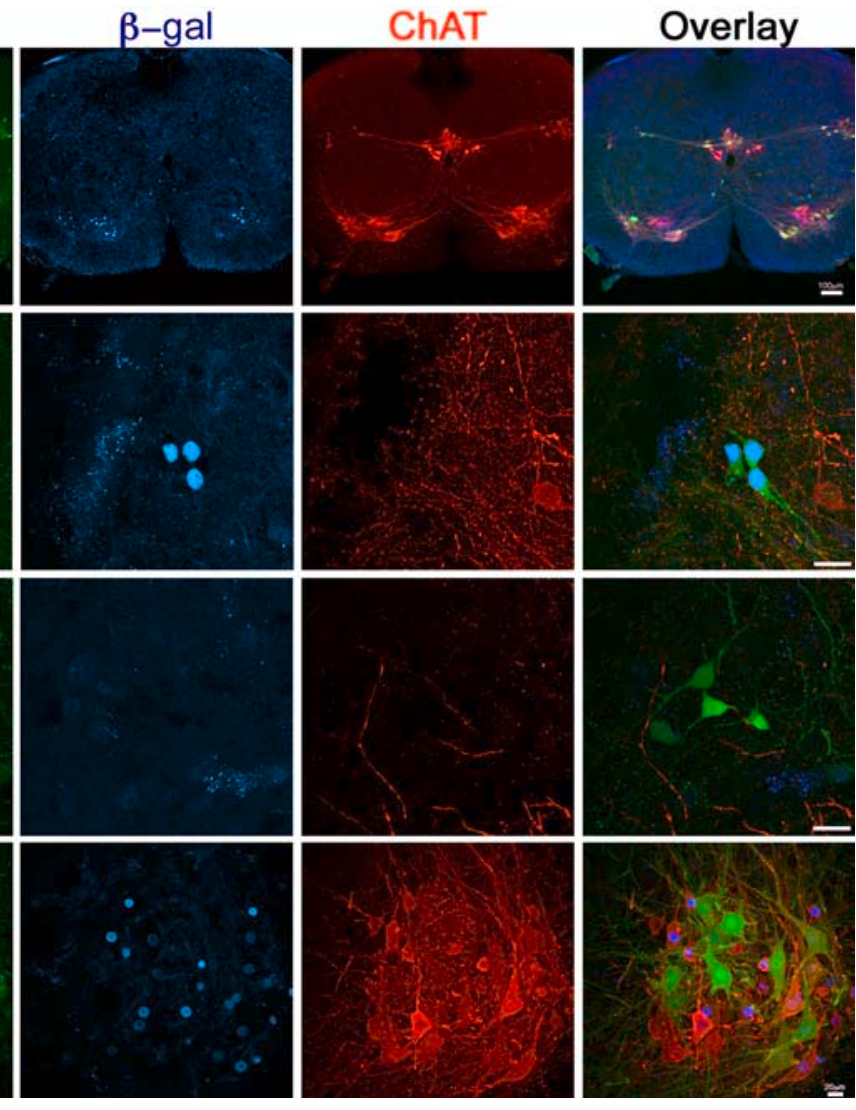

Figure 2. Medial lamina VIII interneurons are $\mathrm{Hb}^{+}{ }^{+} \cdot \boldsymbol{A}, \mathrm{In} \mathrm{Hb9:GFP} \times \mathrm{Hb}^{\text {nlsLacZ/+ }}$ offspring, low-power confocal projections (Hb9) (data not shown). C, Most GFP ${ }^{+}$scattered interneurons throughout the ventral horn are both $\beta$-gal ${ }^{-}$and ChAT ${ }^{-}$. D, Motoneurons identified by ChAT immunoreactivity are $\beta$-gal ${ }^{+}$. Note that not all motoneurons are GFP ${ }^{+}$. Scale bars: $\boldsymbol{B}-\boldsymbol{D}, 20 \mu \mathrm{m}$.

$\mu \mathrm{m}$ section). $\mathrm{Hb}^{+}$interneurons were rarely observed below midlumbar levels. Although not uniformly distributed in the rostrocaudal axis, the mean distribution of these cells was similar at upper thoracic ( 2.4 cells per $30 \mu \mathrm{m}$ section, 43 sections), lower thoracic ( 2.1 cells, 40 sections), and upper lumbar ( 2.2 cells, 25 sections) levels.

In motoneurons, the expression of $\mathrm{Hb} 9$ is associated with a cholinergic phenotype (Tanabe et al., 1998), prompting us to examine whether $\mathrm{GFP}^{+}$interneurons are also cholinergic. In $H b 9: e G F P \times H b 9^{\text {nlsLacZ/+ }}$ double-transgenic mice, $\mathrm{Hb}^{+}{ }^{+}$interneurons lacked ChAT expression (Fig. 2B). We next examined interneuronal expression of Islet class LIM homeodomain proteins, which are expressed in motoneurons (Ericson et al., 1992) and in some $\mathrm{Hb}^{+}$interneurons in Drosophila (Odden et al., 2002). None of the $\mathrm{GFP}^{+}$interneurons in Hb9:eGFP mice expressed Islet proteins (data not shown). Thus, $\mathrm{Hb}^{+}{ }^{+}$interneurons in mice lack both ChAT and Islet protein expression.

To investigate the transmitter phenotype of the $\mathrm{Hb}^{+}$neurons, we began by investigating the colocalization of GFP with various transmitter transporters in axonal terminals. Because the majority of $\mathrm{GFP}^{+}$interneuronal terminals (>75\%) (data not shown) were VGLUT2-immunoreactive (IR), we tested the hypothesis that $\mathrm{Hb} 9^{+}$neurons are VGLUT2 ${ }^{+}$by using combined fluorescent in situ hybridization and immunohistochemistry. VGLUT2 mRNA was expressed in medially located $\mathrm{GFP}^{+}$neurons (Fig. 3Ai-Aiv), most notably the small medial lamina VIII 

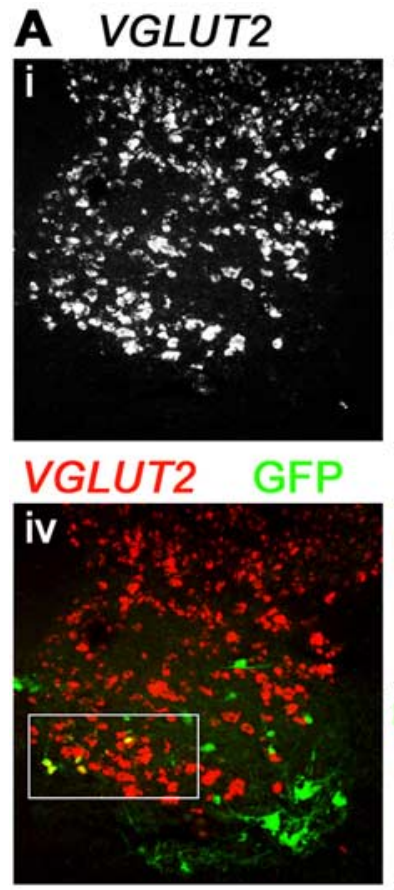

B

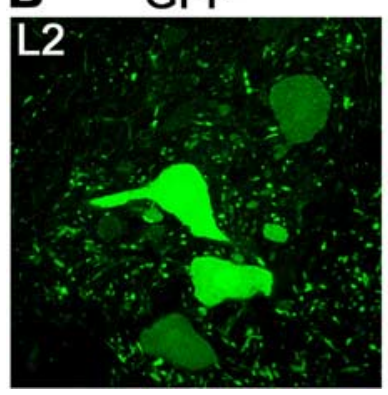

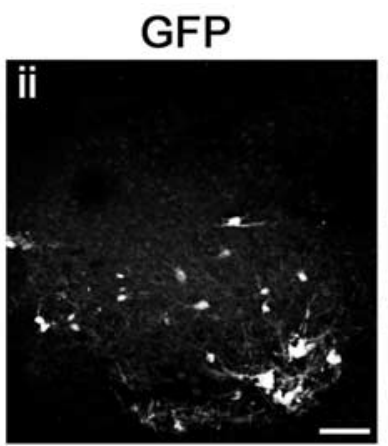
VGLUT2/GFP* VGLUT2/GFP*
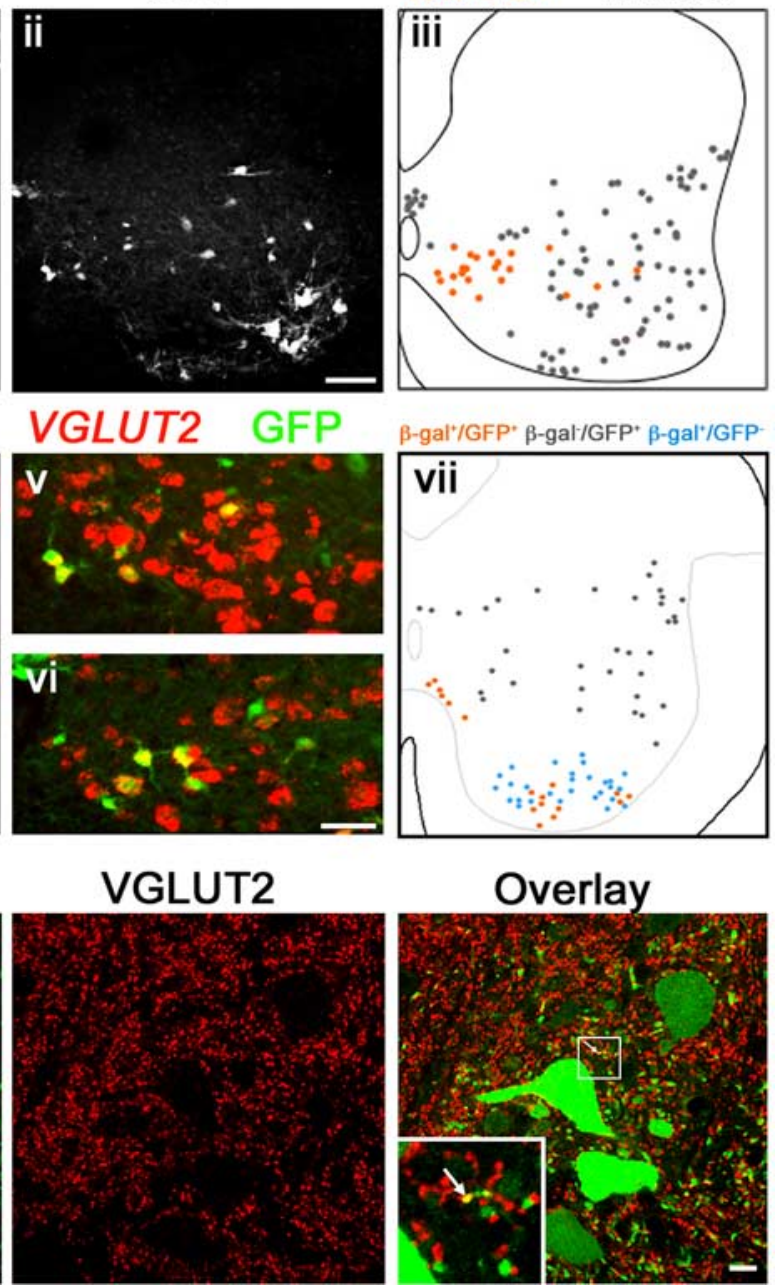

Figure 3. $\mathrm{Hb}^{+}$interneurons are glutamatergic and do not appear to provide a major input to motoneurons. $\boldsymbol{A}$, Confocal images of fluorescence in situ hybridization studies reveal expression of VGLUT2 mRNA (Ai) in cells that express GFP (Aii). All medial GFP ${ }^{+}$neurons contain mRNA for VGLUT2 (Aiv-Avi), including the clustered neurons abutting the ventral commissure recognized as $\mathrm{Hb}^{+}{ }^{+}(\boldsymbol{A v}$ is an enlargement of the box in $\boldsymbol{A i v})$, as well as populations of neurons located more laterally (Avi). Scale bar: (in Aii) for Ai-Aiv, $100 \mu \mathrm{m}$; (in Avi) for $\boldsymbol{A v}-\mathbf{A v i}, 50 \mu \mathrm{m}$. Avii, Neurolucida schematic drawings illustrate the corresponding clustering of $\mathrm{Hb}^{+}{ }^{+}$interneurons abutting the ventral commissure in the $\mathrm{Hb} 9: \mathrm{GFP} \times \mathrm{Hb}^{\text {nlsLacZ/+ }}$ double-transgenic mice. Note that the GFP ${ }^{+}$cells that express VGLUT2 (Aiii) include the $\mathrm{Hb}^{+}{ }^{+}$interneurons (Avii). B, GFP ${ }^{+}$motoneuron somata and proximal dendrites in the lateral motor column in $\mathrm{L} 2$ are devoid of VGLUT2 ${ }^{+} \mathrm{GFP}^{+}$terminals. This image is representative of the thorough scanning of three $70 \mu \mathrm{m}$ sections from L2 in each of three mice. The single VGLUT2 ${ }^{+} \mathrm{GFP}^{+}$terminal in this frame is marked with an arrow and magnified in the inset. Scale bar, $10 \mu \mathrm{m}$.

$\mathrm{Hb9}^{+}$interneurons (Fig. $3 A v$ ), as well as in some larger $\mathrm{GFP}^{+}$ neurons located more laterally (Fig. $3 A v i)$. The similar location of VGLUT2 $^{+} / \mathrm{GFP}^{+}$neurons (Fig. 3 Aiii) and $\mathrm{GFP}^{+} / \mathrm{lacZ}^{+}$neurons (Fig. $3 A v i i$ ) provides evidence that $\mathrm{GFP}^{+}$interneurons in this region, which includes endogenous $\mathrm{Hb}^{+}{ }^{+}$interneurons, are glutamatergic.

To determine whether $\mathrm{Hb}^{+}{ }^{+}$interneurons form direct contacts with motoneurons, we studied the distribution of $\mathrm{GFP}^{+}$/ VGLUT2 ${ }^{+}$terminals in the L2-L4 segments ( $n=7$ mice). However, it should be noted that some $\mathrm{GFP}^{+} / \mathrm{VGLUT}^{+}{ }^{+}$terminals originate from $\mathrm{Hb}^{-}{ }^{-}$neurons (Fig. $3 A$ ). $\mathrm{GFP}^{+} / \mathrm{VGLUT}^{+}{ }^{+}$terminals were the most numerous in lamina VIII and the ventral part of lamina $\mathrm{X}$ but also formed a plexus in the central part of laminas V-VI. Scattered GFP ${ }^{+} / \mathrm{VGLUT}{ }^{+}$boutons were seen in the medial part of lamina VII. There were relatively few $\mathrm{GFP}^{+}$/ VGLUT2 $^{+}$terminals in lamina IX in any of these lumbar seg- ments. In addition, a detailed study of both the medial and lateral motor columns revealed that $\mathrm{GFP}^{+} / \mathrm{VGLUT}^{+}{ }^{+}$terminals were seldom found in contact with motoneuron somata or proximal dendrites (Fig. 3B). Thus, we did not obtain evidence in support of significant input of $\mathrm{Hb} 9$ interneurons to motoneurons. However, it remains possible that the terminals of $\mathrm{Hb} 9$ interneurons are restricted to the distal dendrites of motoneurons. We note that the study by Hinckley et al. (2005) reports detection of a neurobiotin-filled GFP ${ }^{+}$ process in proximity to a $\mathrm{GFP}^{+}$(presumed motoneuron) dendrite in the region between the medial and lateral motor columns, although the status of endogenous $\mathrm{Hb} 9$ expression in this neuron was not determined. Evaluation of the extent of direct connectivity between $\mathrm{Hb} 9$ interneurons and motor neurons will therefore require more detailed study.

We next examined the transmitter phenotype of synaptic terminals that are likely to be presynaptic to $\mathrm{Hb}^{+}$interneurons. Glutamatergic input to $\mathrm{GFP}^{+} \mathrm{Hb}^{+}$interneuron somata and dendrites was detected with antibodies against VGLUT1 (Fig. 4A) and VGLUT2 (Fig. 4B). Virtually all $\mathrm{Hb} 9^{+}$interneurons studied (12 of 13 ) had VGLUT1-IR boutons (3-5 per $60 \mu \mathrm{m}$ section) contacting the somata or proximal dendrites. These VGLUT1-IR terminals on $\mathrm{Hb}^{+}$interneurons likely arise from primary afferents, whereas VGLUT2-IR terminals arise from interneurons (Oliveira et al., 2003; Hughes et al., 2004). VGLUT2-IR GFP ${ }^{+}$terminals were seen on all $\mathrm{GFP}^{+} \mathrm{Hb}^{+}$interneurons, raising the possibility of selfexcitation or mutual re-excitation, a property important in rhythm-generating networks (Roberts and Tunstall, 1990; Rowat and Selverston, 1997). Evidence for inhibitory synaptic input was demonstrated by the presence of both $\mathrm{GAD}-67^{+}$and $\mathrm{GlyT}_{2}{ }^{+}$axons in contact with $\mathrm{GFP}^{+}$ $\mathrm{Hb} 9^{+}$interneurons (Fig. 4C,D). In addition, because serotonin is important in the generation of locomotor rhythm (MacLean et al., 1998; Jiang et al., 1999; Ribotta et al., 2000), we examined serotonergic input to the $\mathrm{GFP}^{+} \mathrm{Hb}^{+}$interneurons and found 5-HT-IR fibers in apposition to these cells (Fig. $4 E$ ). Together, these data suggest that the $\mathrm{Hb}^{+}{ }^{+}$interneurons receive diverse excitatory, inhibitory, and neuromodulatory input.

\section{Electrophysiological properties of medial lamina VIII $\mathrm{GFP}^{+}$interneurons}

The intrinsic properties of neurons involved in the production of rhythmic movement play a critical role in establishing network activity (Getting, 1989). We investigated the intrinsic membrane properties of medial lamina VIII $\mathrm{Hb}^{+}$and other nearby interneurons in vitro using whole-cell patch-clamp recording techniques in acutely prepared spinal cord slices (Carlin et al., 2000) 


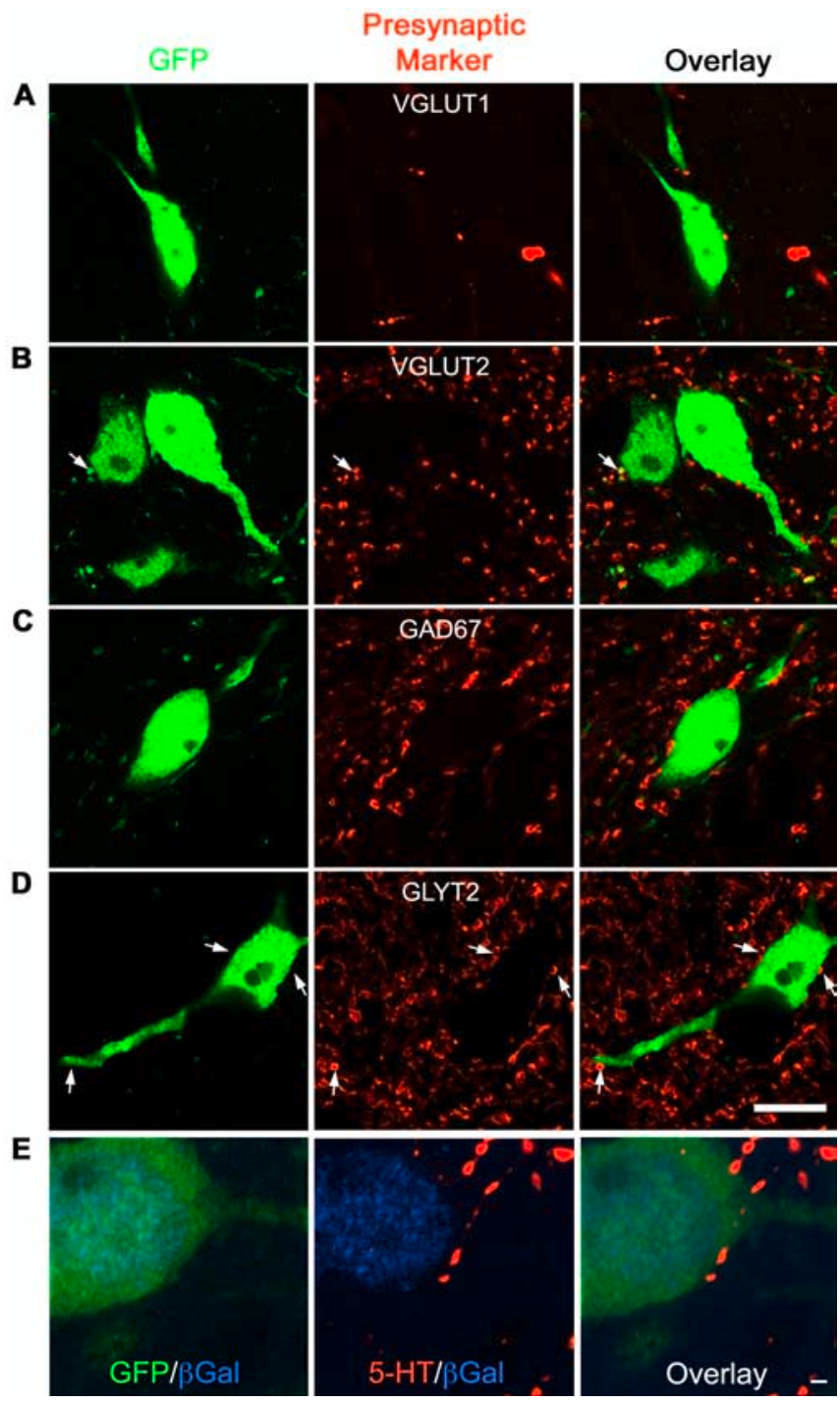

Figure 4. Excitatory and inhibitory inputs to $\mathrm{Hbg}^{+}$interneurons. $\boldsymbol{A}-\boldsymbol{D}$, Single optical section confocal micrographs illustrate VGLUT1 ${ }^{+}(\boldsymbol{A})$ and VGLUT2 ${ }^{+}(\boldsymbol{B})$ axon terminals apposed to medial lamina VIII GFP ${ }^{+}$neurons. Note that some VGLUT2 ${ }^{+}$terminals apposed to the $\mathrm{Hb} 9^{+}$ interneurons are also $\mathrm{GFP}^{+}$and may therefore reflect self- or mutual excitation. There are also $\mathrm{GAD} 67^{+}(\boldsymbol{C})$ and $\mathrm{GlyT2}^{+}(\boldsymbol{D})$ terminals apposed to the $\mathrm{Hb} 9^{+}$interneurons. Scale bar, $10 \mu \mathrm{m}$. $\boldsymbol{E}$, In the $\mathrm{Hb} 9: \mathrm{GFP} \times \mathrm{Hb}^{\text {nlslacz/+ }}$ double-transgenic mouse, $5-\mathrm{HT}^{+}$terminals make contact with $\mathrm{GFP}^{+}$interneurons that are also $\beta$-gal ${ }^{+}\left(\mathrm{Hbg}^{+}\right)$. Scale bar, $1 \mu \mathrm{m}$.

(Figs. 5A, 6A). Current-clamp recordings were obtained from $\mathrm{GFP}^{+}$interneurons located below the central canal and in medial lamina VIII, bordering the ventral commissure.

Based on their size, location, passive membrane properties, and responses to injected current steps, two distinct populations of GFP ${ }^{+}$interneurons could be identified (Table 1 ). The majority were identified as endogenous $\mathrm{Hb}^{+}$interneurons by their size and location (type $1 ; n=57$ ). The $\mathrm{Hb}^{+}{ }^{+}$neurons were small (mean whole-cell capacitance, $10.0 \pm 1.5 \mathrm{pF}$ ) with high input resistances (mean, 903.2 $\pm 226.9 \mathrm{M} \Omega$ ). These input resistances were in a range $(\sim 700 \mathrm{M} \Omega)$ similar to those reported by Hinckley et al. (2005). Approximately one-third (18 of 57) of these cells were spontaneously active, either with tonic firing or with occasional action potentials. The remaining cells in this population did not fire spontaneously and had a mean resting membrane potential of $-51.7 \pm 6.4$ $\mathrm{mV}$. Recordings were also obtained from more lateral GFP ${ }^{+}$interneurons (type $2 ; n=8$ ). The type 2 ectopic $\mathrm{GFP}^{+}$interneurons were not clustered and appeared morphologically distinct from the $\mathrm{Hb}^{+}$ interneurons. Compared with the type 1 cells, these type 2 cells were larger (mean whole-cell capacitance, $16.8 \pm 2.3 \mathrm{pF} ; p<0.005$ ) with correspondingly lower input resistances (517.8 $\pm 169.8 \mathrm{M} \Omega ; p<$ 0.005) (Table 1). These data suggest that $\mathrm{Hb}^{+}$interneurons are both molecularly and electrophysiologically distinct from surrounding neurons.

To examine additional electrophysiological characteristics of these neurons, we studied postinhibitory rebound (PIR), a critical feature in establishing an alternating rhythm in many motor systems (Perkel and Mulloney, 1974; Tegner et al., 1997). The endogenous $\mathrm{Hb}^{+}$interneurons (type 1) (Fig. 5A) exhibited strong PIR that was evoked after the break of a hyperpolarizing current pulse (Fig. 5B,D-F). The PIR reached threshold for action potential generation, followed (within $35 \mathrm{~ms}$ ) by a second action potential, forming a doublet (Fig. $5 B, C, F$ ). Depolarizing steps from $-90 \mathrm{mV}$ led to all-or-none spiking, which, in the presence of TTX, resembled a calcium-mediated spike (Fig. 5C). The amplitude of the PIR was dependent on both the voltage (Fig. $5 B$ ) and time (Fig. 5D) of previous hyperpolarization, consistent with the PIR being mediated by T-type $\left(\mathrm{Ca}_{\mathrm{V}} 3\right)$ calcium channels (Carbone and Lux, 1984; Aizenman and Linden, 1999). This was confirmed by its block with nickel $(100-500 \mu \mathrm{M} ; n=6)$ (Fig. $5 E$ ). In experiments using the Hb9:GFP $\times$ Hb9 ${ }^{\text {nlsLacZ/+ }}$ doubletransgenic mice and intracellular injection of Alexa 594, processing for $\beta$-gal immunoreactivity established that interneurons with PIR expressed $\mathrm{Hb} 9$ (Fig. $5 F$ ). These data indicate that $\mathrm{Hb}^{+}$ interneurons have electrophysiological characteristics important in rhythmogenic networks.

To establish whether this electrophysiological profile was selective for the endogenous $\mathrm{Hb}^{+}{ }^{+}$interneurons, type 2 interneurons that expressed GFP ectopically were also studied (Fig. 6A). Unlike the type 1 neurons, injection of hyperpolarizing current pulses revealed a time-dependent sag that is typical of that mediated by a hyperpolarization-activated mixed cationic conductance $\left(I_{\mathrm{h}}\right)\left(\right.$ Pape, 1996) (Fig. 6B). As a consequence, these $\mathrm{GFP}^{+}$ interneurons exhibited a small depolarization after the break of the hyperpolarizing current pulse, which could be associated with single action potentials. Doublet spike firing was never observed. The majority of these type 2 cells ( 5 of $8 ; 63 \%$ ) exhibited smallamplitude (peak to peak, $3.9 \pm 1.3 \mathrm{mV}$ ) biphasic spontaneous oscillations in their membrane potential that were voltage independent (Fig. 6C, arrows). Such oscillations were not detected in type 1 neurons. Thus, the electrophysiological profile of endogenous $\mathrm{Hb}^{+} \mathrm{GFP}^{+}$neurons appears distinct from other ectopic $\mathrm{GFP}^{+}$interneurons found in close proximity in the ventral spinal cord.

\section{Locomotor-induced Fos expression and conditional bursting} of Hb9-positive interneurons

Recent studies by Hinckley et al. (2005) have provided evidence that the activity of a population of $\mathrm{GFP}^{+}$interneurons in lamina VIII is synchronized to rhythmic ventral root output. To assess whether $\mathrm{Hb}^{+}{ }^{+}$interneurons are activated in locomotion, adult mice were subjected to a $90 \mathrm{~min}$ locomotor task, and their spinal cords were processed for Fos immunohistochemistry (Barajon et al., 1992; Carr et al., 1995; Herdegen and Leah, 1998; Dai et al., 2005). This activity induced Fos expression in these mice in a distribution similar to that demonstrated recently in cat fictive locomotion (Dai et al., 2005). Single small cells and clusters of $\mathrm{GFP}^{+}$interneurons that were morphologically and anatomically homologous to the $\mathrm{Hb}^{+}$interneurons expressed Fos under these conditions ( 1.2 cells per $30 \mu \mathrm{m}$ section; 15 sections per 
A
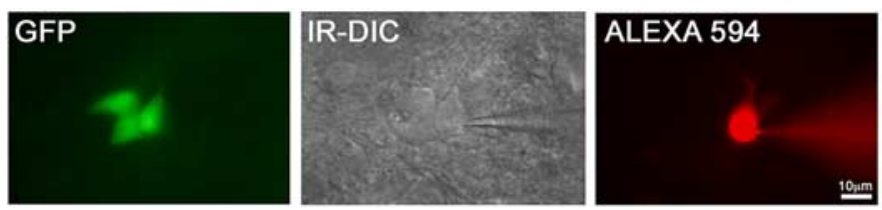

B

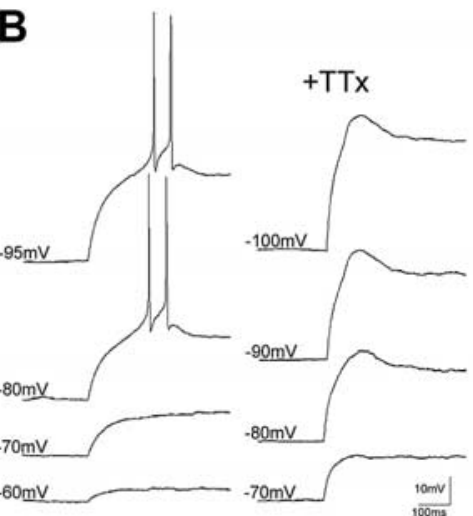

C

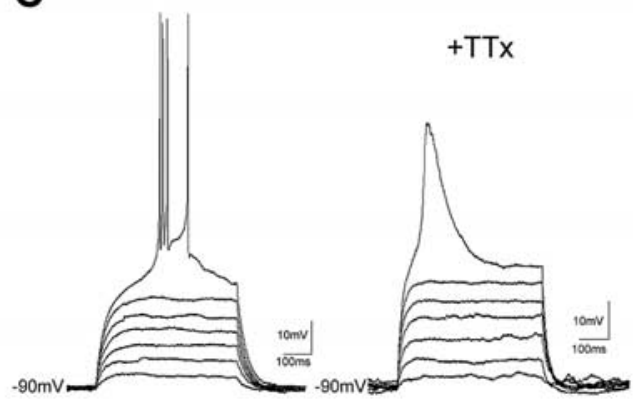

E
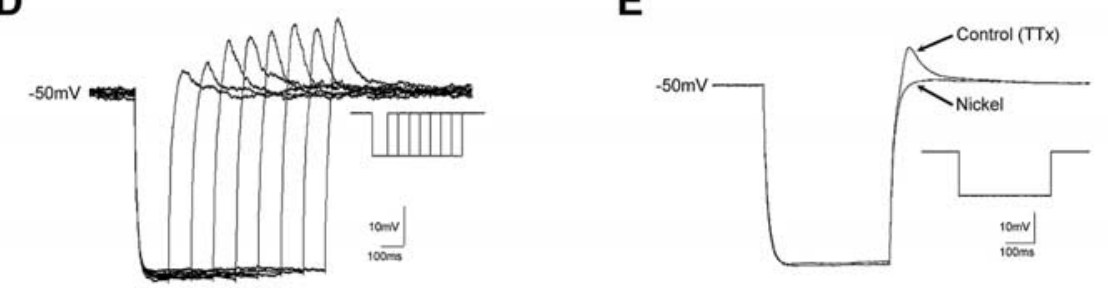

$\mathbf{F}$
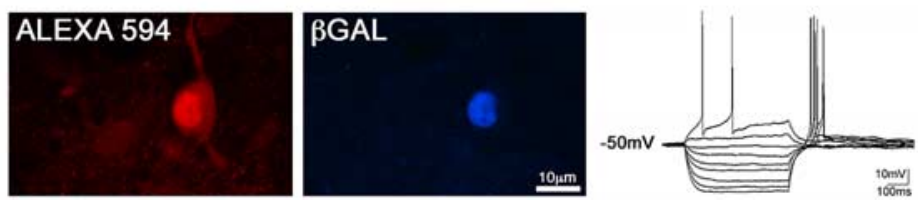

Figure 5. The electrophysiological profile of $\mathrm{Hbg}^{+}$interneurons. $A$, Interneurons identified by the presence of GFP were patch clamped using IR-differential interference contrast (DIC) and filled with Alexa 594. B, The PIR that evokes action potential firing is dependent on the preceding voltage. In TTX, the amplitude of the PIR is dependent on previous membrane voltage. Hyperpolarizing pulses of $500 \mathrm{~ms}$ duration were elicited from $-50 \mathrm{mV}$. C, Injection of linearly increasing current pulses from a holding potential of $-90 \mathrm{mV}$ revealed an all-or-none depolarization that, after reaching threshold, led to a burst of action potentials. In the presence of TTX (1 $\mu \mathrm{m})$, an underlying low-amplitude spike was revealed. $\boldsymbol{D}$, The amplitude of the PIR (in TTX) is dependent on the duration of preceding hyperpolarization. $\boldsymbol{E}$, The PIR is blocked with nickel $(100 \mu \mathrm{M}) . \boldsymbol{F}$, In Hb9:GFP $\times$ Hb9 ${ }^{\text {nlslacZ/+ }}$ doubletransgenic mouse slices, recorded cell somata were filled with the intracellular dye Alexa 594. Immunohistochemical processing after recording revealed colocalization of Alexa 594 with $\beta$-gal, demonstrating that these cells (type 1 ) are indeed $\mathrm{Hbg}^{+}$.

relatively low amplitude $(5.1 \pm 1.3 \mathrm{mV})$ and occurred with a frequency of $0.9 \pm 0.4$ $\mathrm{Hz}$ (Fig. $7 B$ ). These oscillation frequencies were voltage independent (Fig. 7D), consistent with the hypothesis that the oscillations reflect activity in electrotonically coupled neurons that have similar inphase membrane potential oscillations (Sillar and Simmers, 1994). These frequencies are in the range of slow overground locomotion, but faster than the frequencies of fictive stepping illustrated in mouse in vitro spinal cord preparations [ $\sim 0.2 \mathrm{~Hz}$ (Jiang et al., 1999); <0.1 Hz (Hinckley et al., 2005)]. In the remaining three cells, application of these drugs in the presence of TTX resulted in an initial depolarization $(8.9 \pm 0.4 \mathrm{mV})$, followed by the onset of large-amplitude oscillations $(42.5 \pm 2.9 \mathrm{mV})$ with a frequency of $0.4 \pm$ $0.1 \mathrm{~Hz}$ (Fig. 7C). When hyperpolarized to holding potentials of -70 to $-75 \mathrm{mV}$, the depolarized phase of the oscillations initiated an all-or-none type of spike, peaking at $-13.3 \pm 0.5 \mathrm{mV}$ (amplitude, $61.6 \pm 0.6$ $\mathrm{mV}$ ) and decaying to a plateau at $-50.7 \pm$ $2.8 \mathrm{mV}$ before rapid hyperpolarization back to baseline. On additional hyperpolarization, a thresholding effect was seen, in which only some of the depolarizations elicited an all-or-none spike. Additional hyperpolarization eliminated these spikes, leaving smalleramplitude oscillations $(14.0 \pm 3.5 \mathrm{mV})$ of similar frequency $(0.4 \pm 0.1 \mathrm{~Hz})$ (Fig. $7 C)$. In contrast to the lower-amplitude oscillations demonstrated above, these oscillations were voltage-dependent, with hyperpolarization leading to an increase in oscillation frequency (Fig. $7 D$ ), indicating that the frequency of oscillations is determined by intrinsic neuronal properties rather than by the network. The reduction in frequency with depolarization primarily results from a prolongation of the depolarized phase of the oscillation. This likely results from the re-

mouse; $n=2$ mice) (Fig. $7 A$, top panels). In contrast, Fos immunoreactivity was not detected in these neurons in mice that were relatively inactive before perfusion $(n=2)$ (Fig. $7 A$, bottom panels), linking Fos expression to locomotor behavior. Thus, endogenous $\mathrm{Hb}^{+}{ }^{+}$neurons are activated during locomotion.

Rhythmic locomotor output can be induced in the in vitro mouse spinal cord preparation by the application of 5-HT (20 $\mu \mathrm{M})$, dopamine $(50 \mu \mathrm{M})$, and NMDA $(20 \mu \mathrm{M})$ (Jiang et al., 1999). To investigate whether endogenous $\mathrm{Hb}^{+}{ }^{+}$interneurons have intrinsic properties to support rhythmic activity, these three receptor agonists were bath applied to spinal cord slices of mice of a developmental stage sufficient to bear weight and walk (more than or equal to P8). In all 19 type 1 neurons studied under these conditions, application resulted in an increase in spontaneous activity. After the addition of TTX $(1 \mu \mathrm{M})$, oscillations in membrane potential were recorded (11 of 19 neurons), indicating that the membrane potential of these cells can oscillate in the absence of synaptic activation. In 8 of 11 neurons, these oscillations were cruitment of slowly inactivating inward conductances.

To investigate the contribution of the $\mathrm{Ca}_{\mathrm{V}} 3$-mediated calcium conductance to this intrinsic oscillatory activity, nickel $(100 \mu \mathrm{M})$ was added to the bath $(n=2)$. Nickel blocked the largeamplitude spike, leaving small-amplitude $(7.8 \pm 1.8 \mathrm{mV})$ oscillations with waveforms similar to those seen in the cells described above. The frequency was relatively unaffected $(0.3 \pm 0.1 \mathrm{~Hz})$ (Fig. 7C). The large-amplitude oscillations in these three cells may result from more intact dendritic arborizations with their associated currents. These data show that the $\mathrm{Hb}^{+}$(type 1) interneurons are capable of endogenous rhythmic oscillatory activity under the same conditions that evoke rhythmic locomotor output in the in vitro spinal cord preparation. The largeamplitude oscillations evoked by the locomotor stimuli depend on the conductance that underlies the PIR (nickel-sensitive calcium conductance). These biophysical studies of endogenous $\mathrm{Hb} 9^{+}$interneurons support the idea that phasic activity of these neurons may contribute to rhythmic locomotor output. 


\section{Discussion}

The spinal cord circuitry involved in the generation of rhythmic locomotor activity has remained elusive, primarily as a consequence of the technical challenges of identifying relevant populations of interneurons. In this study, we analyzed transgenic mice that express GFP in a small set of $\mathrm{Hb}{ }^{+}$interneurons to define the anatomical and physiological properties of a population of excitatory spinal interneurons that express many of the characteristics expected of interneurons involved in locomotor rhythm generation.

In embryonic mammals, the homeobox gene $H b 9$ is expressed by newly generated motoneurons (Pfaff et al., 1996; Saha et al., 1997; Tanabe et al., 1998; Thaler et al., 1999) and functions in the consolidation of motoneuron fate (Arber et al., 1999). Neuronal expression of $\mathrm{Hb} 9$ continues into adulthood (Vult von Steyern et al., 1999), and GFP expression driven by an $\mathrm{Hb} 9$ promoter can be used to identify Hb9-expressing neurons in the postnatal spinal cord (Wichterle et al., 2002). The Hb9-GFP and Hb9 $9^{\text {nlsLacZ }}$ transgenic mice permit the identification and characterization of a population of spinal interneurons defined by endogenous $\mathrm{Hb} 9$ expression. These interneurons constitute an anatomically and electrophysiologically homogeneous population.

To date, it has not been possible to define a discrete population of spinal interneurons based on genetic criteria. The expression of transcription factors has been used to classify ventral interneurons into four major subgroups (V0-V3), each with some common features (Briscoe et al., 2000). However, it is clear, given the diversity of spinal interneurons, that there are many distinct populations within each domain (Goulding and Lamar, 2000). In Xenopus and zebrafish, a single homogeneous population of inhibitory spinal interneurons expresses the transcription factor engrailed-1 (Higashijima et al., 2004; Li et al., 2004). However, in mammals, engrailed-1-expressing V1-derived interneurons develop into diverse functional populations that include Renshaw cells as well as other interneuronal populations (Sapir et al., 2004). Similarly, V0 $\mathrm{Dbx}^{+}$progenitors give rise to a heterogeneous population of commissural inhibitory interneurons (Pierani et al., 2001), some of which are likely involved in locomotor activity, because interlimb coordination is disrupted in embryonic $D b \times 1$ knock-out animals that lack V0 neurons (Lanuza et al., 2004).

Although it has been documented that $\mathrm{Hb} 9$ is involved in motoneuron development (Arber et al., 1999; Thaler et al., 1999), its role in interneuron differentiation is unclear. In Drosophila, $\mathrm{Hb} 9$ is expressed not only in somatic motoneurons but also in two populations of interneurons (Broihier and Skeath, 2002; Odden et al., 2002), one of which expresses the Islet transcription factor and the neurotransmitter serotonin. However, in the mouse, $\mathrm{Hb}^{+}{ }^{+}$interneurons are not serotonergic (Fig. $4 E$ ), nor do they express Isl1/2 (data not shown). It remains to be seen whether vertebrate $\mathrm{Hb} 9^{+}$interneurons are homologous to the ventral cluster of six $\mathrm{Hb}^{+}{ }^{+}$Islet $^{-}$(VHI) interneurons in Drosophila (Odden et al., 2002).
Table 1. Comparison of electrophysiological properties of $\mathrm{Hb}^{+}$(type 1) and non$\mathrm{Hbg}^{+}$(type 2) interneurons

\begin{tabular}{lcc}
\hline Membrane property & Type 1 $(n=57)$ & Type 2 $(n=8)$ \\
\hline Percentage with spontaneous firing & 31.6 & 100 \\
Percentage with biphasic subthreshold oscillations & 0 & 63 \\
Resting membrane potential $(\mathrm{mV})$ & $-51.7 \pm 6.4$ & $\mathrm{ND}$ \\
Membrane capacitance $(\mathrm{pF})$ & $10.0 \pm 1.5$ & $16.8 \pm 2.3^{*}$ \\
Input resistance $(\mathrm{M} \Omega)$ & $903 \pm 227$ & $517 \pm 170^{* *}$ \\
Percentage with PIR-evoked doublets & 100 & 0 \\
Percentage with time-dependent rectifier & 0 & 100 \\
\hline
\end{tabular}

ND, Not determined (could not be determined because of spontaneous activity). ${ }^{*} p=0.00025 ;{ }^{* *} p=0.0021$.

In the mouse, endogenous $\mathrm{Hb}^{+}{ }^{+}$interneurons are found in the cervical, thoracic, and upper lumbar spinal cord abutting the ventral commissure. Few interneurons in this region have been characterized, although some lamina VIII interneurons have tk;2been described. Long ascending and descending fibers originate from neurons in lamina VIII (Molenaar and Kuypers, 1978). However, Hb9 ${ }^{+}$ neurons are located dorsal to these populations. Furthermore, the presence of numerous VGLUT2 ${ }^{+}, \mathrm{GFP}^{+}$terminals in the vicinity of their cell bodies suggests that the $\mathrm{Hb}^{+}{ }^{+}$interneurons may have an axonal arborization at or near the segmental level of their somata. Approximately $85 \%$ of lamina VIII interneurons are commissural (Scheibel, 1969), but those studied are located caudal and lateral to Hb9 ${ }^{+}$interneurons (Bannatyne et al., 2003; Jankowska et al., 2003; Matsuyama et al., 2004).

Very few populations of excitatory interneurons involved in locomotion have been defined in the ventral spinal cord, although some are involved in pattern generation (Buchanan et al., 1989; Roberts and Sillar, 1990). In the mouse, excitatory interneurons important for interlimb coordination have been described: EphA4 receptor and ephrin B3 knock-out mice hop rather than walk, likely because aberrant crossing of excitatory 

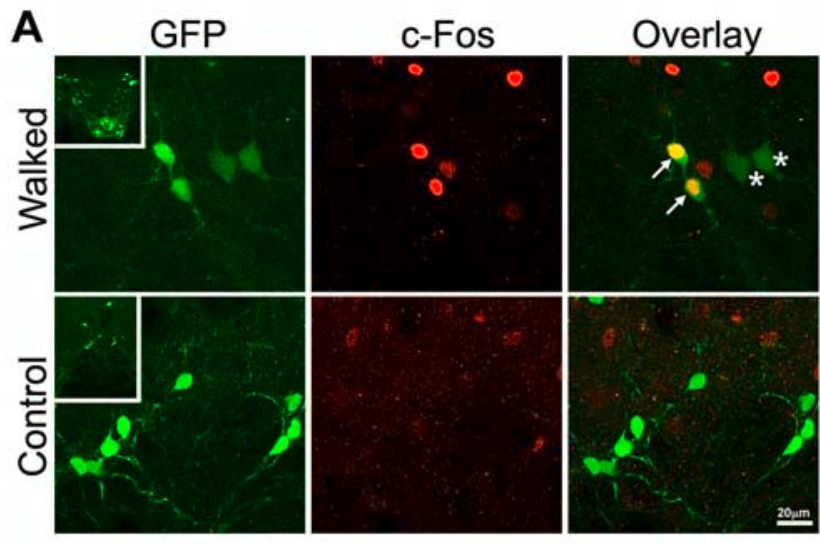

B
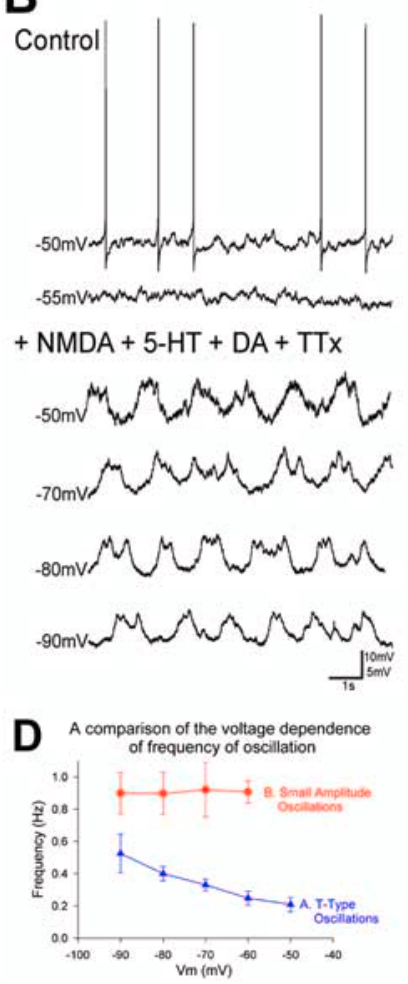

\section{Control}

$-55 \mathrm{mV}$

+ NMDA + 5-HT + DA + TTX
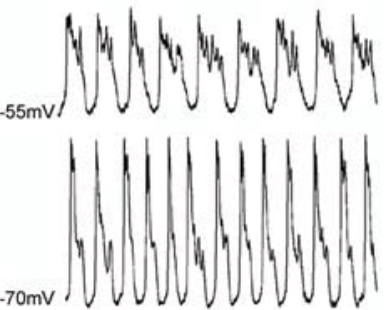

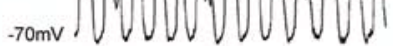
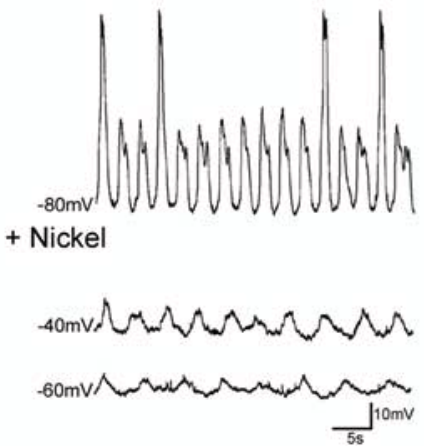

+ Nickel

Figure 7. $\mathrm{Hbg}^{+}$interneurons are active during locomotion and are conditionally rhythmic. A, Adult mice were subjected to 90 min of walking to induce activity-dependent Fos expression. Confocal micrographs illustrate Fos immunoreactivity in the clustered medial lamina VIII Hb9 ${ }^{+}$ interneurons (arrows) but not in the more lateral larger $\mathrm{GFP}^{+}\left(\mathrm{Hb9}^{-}\right)$interneurons (asterisks). In the control condition, mice slept before perfusion, and the $\mathrm{Hb}^{+}{ }^{+}$interneurons were Fos ${ }^{-}$. Experimental and control experiments were both conducted at mid-day. Low-magnification insets indicate location of the interneurons abutting the ventral commissure. $\boldsymbol{B}-\boldsymbol{D}$, Application of the neurotransmitters 5-HT $(20 \mu \mathrm{M})$, dopamine (DA; $50 \mu \mathrm{M})$, and NMDA $(20 \mu \mathrm{M})$ in the presence of TTX (1 $\mu \mathrm{m})$ induced two distinct waveforms of endogenous activity in $\mathrm{Hb}^{+}$cells. $\boldsymbol{B}$, In some $\mathrm{Hbg}^{+}$neurons, small-amplitude subthreshold oscillations were evoked. The amplitude of these oscillations was voltage independent. $\mathbf{C}$, In other $\mathrm{Hb}^{+}$neurons, large oscillations in membrane potential could reach threshold for calcium spikes. Note the all-or-none nature of the activation of the calcium spike. The amplitude of these oscillations was voltage dependent, with a voltage window where calcium spikes were evoked. This large calcium spike component of the oscillations was blocked by nickel (100 $\mu \mathrm{m})$, leaving small-amplitude oscillations. $\boldsymbol{D}$, The frequency of the large-amplitude oscillations was voltage dependent, whereas the frequency of the smaller-amplitude oscillations was independent of membrane potential.

EphA4 ${ }^{+}$neurons resulted in the synchronous locomotor phenotype observed (Kullander et al., 2003). However, the function and connectivity of neurons with aberrant crossing in the EphA4 mutants have yet to be identified.

A recent study examining the connectivity of lamina VIII $\mathrm{Hb9}: \mathrm{GFP}^{+}$neurons in the early postnatal lumbar spinal cord has suggested that these are last-order interneurons (Hinckley et al., 2005). In these studies, the connectivity of $\mathrm{GFP}^{+}$interneurons was assessed in the absence of information on the status of endogenous $\mathrm{Hb} 9$ expression. Because only a minority of eGFP+ interneurons express endogenous $\mathrm{Hb} 9$ and there is no demonstrated homogeneity of electrophysiological properties of the neurons studied by Hinckley et al. (2005), it remains possible that the $\mathrm{eGFP}^{+}$interneurons found to form direct contacts with motoneurons are distinct from the endogenous $\mathrm{Hb} 9$ interneuron population. Our studies could not confirm the last-order status of endogenous $\mathrm{Hb}^{+}{ }^{+}$interneurons: we rarely detected $\mathrm{GFP}^{+}$ VGLUT2 ${ }^{+}$terminals on motoneuron somata or proximal dendrites. However, it cannot be excluded that contacts are formed with the distal dendrites of motoneurons. Resolving with greater certainty whether endogenous $\mathrm{Hb} 9$ interneurons form direct synaptic contacts with motoneurons is imperative, given the evidence that this population of interneurons may contribute to rhythmic motor output.

\section{A possible role for $\mathrm{Hb}^{+}{ }^{+}$interneurons in locomotor rhythm generation}

Several features of $\mathrm{Hb}^{+}{ }^{+}$interneurons suggest their possible involvement in rhythm generation. First, the distribution of these neurons (from cervical to upper lumbar spinal cord with few seen caudal to midlumbar segments) is similar to that shown for hindlimb locomotor rhythm-generating networks (Cazalets et al., 1996; Kjaerulff and Kiehn, 1996; Cowley and Schmidt, 1997; Kiehn and Kjaerulff, 1998; Marcoux and Rossignol, 2000).

Second, they receive diverse types of inputs. Serotonergic input is critical in activating the rhythm generator in mammals including the mature mouse (Jiang et al., 1999), neonatal rat (MacLean et al., 1998), and adult cat (Ribotta et al., 2000). In addition, the presence of $\mathrm{VGLUT}^{+} \mathrm{GFP}^{+}$terminals on the $\mathrm{Hb}^{+}$interneurons raises the possibility that self-excitation or mutual excitation has a role in their function. Evidence from other rhythm-generating networks has revealed a prominent role for mutual excitation or self-excitation (Rowat and Selverston, 1997), in which the combination of PIR with mutual reexcitation can facilitate a sustained rhythm (Roberts and Tunstall, 1990).

Third, the electrophysiological properties of $\mathrm{Hb}^{+}{ }^{+}$interneurons are also suited for rhythm generation. $\mathrm{Hb}^{+}{ }^{+}$interneurons exhibit prominent PIR, mediated by a low-threshold, nickelsensitive calcium conductance. In other rhythm-generating networks, it has been established that connectivity alone is insufficient to generate rhythm: the intrinsic properties of the network interneurons determine the rhythm and pattern of output (Perkel and Mulloney, 1974; Hartline and Gassie, 1979; Mulloney et al., 1981; Eisen and Marder, 1984; Harris-Warrick et al., 1995; Roberts et al., 1995; Tegner et al., 1997; Arshavsky et al., 1998; Pena et al., 2004). In particular, PIR has been shown to be an essential property in many rhythm-generating neurons. In different networks, this property may facilitate bursting (Perkel and Mulloney, 1974), ensure that the rhythm is sustained (Roberts and Tunstall, 1990), or improve the stability of the rhythm (Tegner et al., 1997). Thus, $\mathrm{Hb}^{+}{ }^{+}$interneurons have the properties expected for neurons involved in rhythm-generating networks.

It has been demonstrated recently that $\mathrm{Hb}{ }^{+}$interneurons are rhythmically active during locomotor-like ventral root discharges (Hinckley et al., 2005). We found that $\mathrm{Hb}^{+}{ }^{+}$interneurons are activated during overground locomotion, as shown by 
Fos expression elicited by a walking task (Fig. 7A) (Carr et al., 1995; Wilson et al., 2003). Neurons in this region have been shown to be recruited during locomotor-like activity (Kjaerulff et al., 1994; Cina and Hochman, 2000; Dai et al., 2005), and medial lamina VII and lamina X interneurons have been shown to oscillate rhythmically in response to NMDA (Hochman et al., 1994; Kiehn et al., 1996). Furthermore, $\mathrm{Hb}^{+}{ }^{+}$interneurons are intrinsic oscillators; in the presence of TTX, they have large-amplitude oscillations in response to serotonin, dopamine, and NMDA, the same combination of transmitters that evoke locomotor activity in the isolated mouse spinal cord (Cowley and Schmidt, 1994; Jiang et al., 1999). In addition, other stimuli that evoke locomotor activity, including increased extracellular $\mathrm{K}^{+}$concentration (Bracci et al., 1998), or the addition of $\mathrm{K}^{+}$channel blockers (Taccola and Nistri, 2004), evoke rhythmic oscillations in $\mathrm{Hb}^{+}{ }^{+}$interneurons (Wilson and Brownstone, 2004) (J. M. Wilson and R. M. Brownstone, unpublished data). Furthermore, the voltage independence of the oscillation frequency is consistent with activity produced in electrotonically coupled oscillating networks (Sillar and Simmers, 1994). Together with data demonstrating that electrotonic coupling can function to synchronize and pattern spinal locomotor network activity (Kiehn and Tresch, 2002; Taccola and Nistri, 2004), these data support the idea that $\mathrm{Hb}^{+}$ interneurons may be involved in generating locomotor activity.

In conclusion, our findings demonstrate that the genetic dissection of spinal interneuron circuitry based on selective profiles of transcription factor expression combined with electrophysiological analysis can provide insight into locomotor function. The biophysical properties of $\mathrm{Hb}{ }^{+}$interneurons documented in this study lend intriguing, albeit incomplete, support for the view that this set of interneurons has a role in rhythm generation in spinal locomotor circuits.

\section{References}

Aizenman CD, Linden DJ (1999) Regulation of the rebound depolarization and spontaneous firing patterns of deep nuclear neurons in slices of rat cerebellum. J Neurophysiol 82:1697-1709.

Arber S, Han B, Mendelsohn M, Smith M, Jessell TM, Sockanathan S (1999) Requirement for the homeobox gene $\mathrm{Hb} 9$ in the consolidation of motor neuron identity. Neuron 23:659-674.

Arshavsky YI, Deliagina TG, Orlovsky GN, Panchin YV, Popova LB, Sadreyev RI (1998) Analysis of the central pattern generator for swimming in the mollusk Clione. Ann NY Acad Sci 860:51-69.

Baev KV, Degtiarenko AM, Zavadskaia TV, Kostiuk PG (1979) Impulse activity of interneurons of the lumbar portion of the spinal cord during the late long discharges in the motor nerves of immobilized thalamic cats. Neirofiziologiia 11:236-244.

Bannatyne BA, Edgley SA, Hammar I, Jankowska E, Maxwell DJ (2003) Networks of inhibitory and excitatory commissural interneurons mediating crossed reticulospinal actions. Eur J Neurosci 18:2273-2284.

Barajon I, Gossard JP, Hultborn H (1992) Induction of fos expression by activity in the spinal rhythm generator for scratching. Brain Res 588:168-172.

Bracci E, Beato M, Nistri A (1998) Extracellular K+ induces locomotor-like patterns in the rat spinal cord in vitro: comparison with NMDA or 5-HT induced activity. J Neurophysiol 79:2643-2652.

Briscoe J, Pierani A, Jessell TM, Ericson J (2000) A homeodomain protein code specifies progenitor cell identity and neuronal fate in the ventral neural tube. Cell 101:435-445.

Broihier HT, Skeath JB (2002) Drosophila homeodomain protein dHb9 directs neuronal fate via crossrepressive and cell-nonautonomous mechanisms. Neuron 35:39-50.

Brown T (1911) The intrinsic factors in the act of progression in the mammal. Proc R Soc Lond B Biol Sci 84:308-319.

Buchanan JT, Grillner S, Cullheim S, Risling M (1989) Identification of excitatory interneurons contributing to generation of locomotion in lamprey: structure, pharmacology, and function. J Neurophysiol 62:59-69.
Butt SJ, Kiehn O (2003) Functional identification of interneurons responsible for left-right coordination of hindlimbs in mammals. Neuron 38:953-963.

Butt SJ, Harris-Warrick RM, Kiehn O (2002) Firing properties of identified interneuron populations in the mammalian hindlimb central pattern generator. J Neurosci 22:9961-9971.

Carbone E, Lux HD (1984) A low voltage-activated, fully inactivating Ca channel in vertebrate sensory neurones. Nature 310:501-502.

Carlin KP, Jiang Z, Brownstone RM (2000) Characterization of calcium currents in functionally mature mouse spinal motoneurons. Eur J Neurosci 12:1624-1634.

Carr PA, Huang A, Noga BR, Jordan LM (1995) Cytochemical characteristics of cat spinal neurons activated during fictive locomotion. Brain Res Bull 37:213-218.

Cazalets JR, Borde M, Clarac F (1996) The synaptic drive from the spinal locomotor network to motoneurons in the newborn rat. J Neurosci 16:298-306.

Choi T, Huang M, Gorman C, Jaenisch R (1991) A generic intron increases gene expression in transgenic mice. Mol Cell Biol 11:3070-3074.

Cina C, Hochman S (2000) Diffuse distribution of sulforhodamine-labeled neurons during serotonin-evoked locomotion in the neonatal rat thoracolumbar spinal cord. J Comp Neurol 423:590-602.

Cowley KC, Schmidt BJ (1994) A comparison of motor patterns induced by $\mathrm{N}$-methyl-D-aspartate, acetylcholine and serotonin in the in vitro neonatal rat spinal cord. Neurosci Lett 171:147-150.

Cowley KC, Schmidt BJ (1997) Regional distribution of the locomotor pattern-generating network in the neonatal rat spinal cord. J Neurophysiol 77:247-259.

Dai X, Noga BR, Douglas JR, Jordan LM (2005) Localization of spinal neurons activated during locomotion using the $\mathrm{c}$-fos immunohistochemical method. J Neurophysiol 93:3442-3452.

Eisen JS, Marder E (1984) A mechanism for production of phase shifts in a pattern generator. J Neurophysiol 51:1375-1393.

Ericson J, Thor S, Edlund T, Jessell TM, Yamada T (1992) Early stages of motor neuron differentiation revealed by expression of homeobox gene Islet-1. Science 256:1555-1560.

Ericson J, Rashbass P, Schedl A, Brenner-Morton S, Kawakami A, van Heyningen V, Jessell TM, Briscoe J (1997) Pax6 controls progenitor cell identity and neuronal fate in response to graded Shh signaling. Cell 90:169-180.

Getting PA (1989) Emerging principles governing the operation of neural networks. Annu Rev Neurosci 12:185-204.

Gossard JP, Brownstone RM, Barajon I, Hultborn H (1994) Transmission in a locomotor-related group Ib pathway from hindlimb extensor muscles in the cat. Exp Brain Res 98:213-228.

Goulding M, Lamar E (2000) Neuronal patterning: making stripes in the spinal cord. Curr Biol 10:R565-R568.

Goulding M, Lanuza G, Sapir T, Narayan S (2002) The formation of sensorimotor circuits. Curr Opin Neurobiol 12:508-515.

Harris-Warrick RM, Coniglio LM, Levini RM, Gueron S, Guckenheimer J (1995) Dopamine modulation of two subthreshold currents produces phase shifts in activity of an identified motoneuron. J Neurophysiol 74:1404-1420.

Hartline DK, Gassie Jr DV (1979) Pattern generation in the lobster (Panulirus) stomatogastric ganglion. I. Pyloric neuron kinetics and synaptic interactions. Biol Cybern 33:209-222.

Herdegen T, Leah JD (1998) Inducible and constitutive transcription factors in the mammalian nervous system: control of gene expression by Jun, Fos and Krox, and CREB/ATF proteins. Brain Res Brain Res Rev 28:370-490.

Higashijima S, Masino MA, Mandel G, Fetcho JR (2004) Engrailed-1 expression marks a primitive class of inhibitory spinal interneuron. J Neurosci 24:5827-5839.

Hinckley CA, Hartley R, Wu L, Todd A, Ziskind-Conhaim L (2005) Locomotor-like rhythms in a genetically distinct cluster of interneurons in the mammalian spinal cord. J Neurophysiol 93:1439-1449.

Hochman S, Jordan LM, Schmidt BJ (1994) TTX-resistant NMDA receptor-mediated voltage oscillations in mammalian lumbar motoneurons. J Neurophysiol 72:2559-2562.

Huang A, Noga BR, Carr PA, Fedirchuk B, Jordan LM (2000) Spinal cholinergic neurons activated during locomotion: localization and electrophysiological characterization. J Neurophysiol 83:3537-3547.

Hughes DI, Polgar E, Shehab SA, Todd AJ (2004) Peripheral axotomy induces depletion of the vesicular glutamate transporter VGLUT1 in central terminals of myelinated afferent fibres in the rat spinal cord. Brain Res 1017:69-76. 
Jankowska E (1992) Interneuronal relay in spinal pathways from proprioceptors. Prog Neurobiol 38:335-378.

Jankowska E, Hammar I, Slawinska U, Maleszak K, Edgley SA (2003) Neuronal basis of crossed actions from the reticular formation on feline hindlimb motoneurons. J Neurosci 23:1867-1878.

Jessell TM (2000) Neuronal specification in the spinal cord: inductive signals and transcriptional codes. Nat Rev Genet 1:20-29.

Jiang Z, Carlin KP, Brownstone RM (1999) An in vitro functionally mature mouse spinal cord preparation for the study of spinal motor networks. Brain Res 816:493-499.

Kiehn O, Kjaerulff O (1998) Distribution of central pattern generators for rhythmic motor outputs in the spinal cord of limbed vertebrates. Ann NY Acad Sci 860:110-129.

Kiehn O, Tresch MC (2002) Gap junctions and motor behavior. Trends Neurosci 25:108-115.

Kiehn O, Johnson BR, Raastad M (1996) Plateau properties in mammalian spinal interneurons during transmitter-induced locomotor activity. Neuroscience 75:263-273.

Kjaerulff O, Kiehn O (1996) Distribution of networks generating and coordinating locomotor activity in the neonatal rat spinal cord in vitro: a lesion study. J Neurosci 16:5777-5794.

Kjaerulff O, Barajon I, Kiehn O (1994) Sulphorhodamine-labelled cells in the neonatal rat spinal cord following chemically induced locomotor activity in vitro. J Physiol (Lond) 478:265-273.

Kullander K, Butt SJ, Lebret JM, Lundfald L, Restrepo CE, Rydstrom A, Klein R, Kiehn O (2003) Role of EphA4 and EphrinB3 in local neuronal circuits that control walking. Science 299:1889-1892.

Lanuza GM, Gosgnach S, Pierani A, Jessell TM, Goulding M (2004) Genetic identification of spinal interneurons that coordinate left-right locomotor activity necessary for walking movements. Neuron 42:375-386.

Leong SK, Ling EA (1990) Labelling neurons with fluorescent dyes administered via intravenous, subcutaneous or intraperitoneal route. J Neurosci Methods 32:15-23.

Li WC, Higashijima S, Parry DM, Roberts A, Soffe SR (2004) Primitive roles for inhibitory interneurons in developing frog spinal cord. J Neurosci 24:5840-5848.

MacLean JN, Cowley KC, Schmidt BJ (1998) NMDA receptor-mediated oscillatory activity in the neonatal rat spinal cord is serotonin dependent. J Neurophysiol 79:2804-2808.

Marcoux J, Rossignol S (2000) Initiating or blocking locomotion in spinal cats by applying noradrenergic drugs to restricted lumbar spinal segments. J Neurosci 20:8577-8585.

Matsuyama K, Nakajima K, Mori F, Aoki M, Mori S (2004) Lumbar commissural interneurons with reticulospinal inputs in the cat: morphology and discharge patterns during fictive locomotion. J Comp Neurol 474:546-561.

Molenaar I, Kuypers HG (1978) Cells of origin of propriospinal fibers and of fibers ascending to supraspinal levels. A HRP study in cat and rhesus monkey. Brain Res 152:429-450.

Mulloney B, Perkel DH, Budelli RW (1981) Motor-pattern production: interaction of chemical and electrical synapses. Brain Res 229:25-33.

Nakayama K, Nishimaru H, Kudo N (2002) Basis of changes in left-right coordination of rhythmic motor activity during development in the rat spinal cord. J Neurosci 22:10388-10398.

Odden JP, Holbrook S, Doe CQ (2002) Drosophila HB9 is expressed in a subset of motoneurons and interneurons, where it regulates gene expression and axon pathfinding. J Neurosci 22:9143-9149.

Oliveira AL, Hydling F, Olsson E, Shi T, Edwards RH, Fujiyama F, Kaneko T, Hokfelt T, Cullheim S, Meister B (2003) Cellular localization of three vesicular glutamate transporter mRNAs and proteins in rat spinal cord and dorsal root ganglia. Synapse 50:117-129.

Pape HC (1996) Queer current and pacemaker: the hyperpolarizationactivated cation current in neurons. Annu Rev Physiol 58:299-327.

Pena F, Parkis MA, Tryba AK, Ramirez JM (2004) Differential contribution of pacemaker properties to the generation of respiratory rhythms during normoxia and hypoxia. Neuron 43:105-117.

Perkel DH, Mulloney B (1974) Motor pattern production in reciprocally inhibitory neurons exhibiting postinhibitory rebound. Science 185:181-183.

PfaffSL, Mendelsohn M, Stewart CL, Edlund T, Jessell TM (1996) Requirement for LIM homeobox gene Isl1 in motor neuron generation reveals a motor neuron-dependent step in interneuron differentiation. Cell 84:309-320.

Pierani A, Brenner-Morton S, Chiang C, Jessell TM (1999) A sonic hedgehog-independent, retinoid-activated pathway of neurogenesis in the ventral spinal cord. Cell 97:903-915.

Pierani A, Moran-Rivard L, Sunshine MJ, Littman DR, Goulding M, Jessell TM (2001) Control of interneuron fate in the developing spinal cord by the progenitor homeodomain protein Dbx1. Neuron 29:367-384.

Price SR, De Marco Garcia NV, Ranscht B, Jessell TM (2002) Regulation of motor neuron pool sorting by differential expression of type II cadherins. Cell 109:205-216.

Ribotta MG, Provencher J, Feraboli-Lohnherr D, Rossignol S, Privat A, Orsal D (2000) Activation of locomotion in adult chronic spinal rats is achieved by transplantation of embryonic raphe cells reinnervating a precise lumbar level. J Neurosci 20:5144-5152.

Roberts A, Sillar KT (1990) Characterization and function of spinal excitatory interneurons with commissural projections in Xenopus laevis embryos. Eur J Neurosci 2:1051-1062.

Roberts A, Tunstall MJ (1990) Mutual re-excitation with post-inhibitory rebound: a simulation study on the mechanisms for locomotor rhythm generation in the spinal cord of Xenopus embryos. Eur J Neurosci 2:11-23.

Roberts A, Tunstall MJ, Wolf E (1995) Properties of networks controlling locomotion and significance of voltage dependency of NMDA channels: stimulation study of rhythm generation sustained by positive feedback. J Neurophysiol 73:485-495.

Rowat PF, Selverston AI (1997) Synchronous bursting can arise from mutual excitation, even when individual cells are not endogenous bursters. J Comput Neurosci 4:129-139.

Saha MS, Miles RR, Grainger RM (1997) Dorsal-ventral patterning during neural induction in Xenopus: assessment of spinal cord regionalization with xHB9, a marker for the motor neuron region. Dev Biol 187:209-223.

Sapir T, Geiman EJ, Wang Z, Velasquez T, Mitsui S, Yoshihara Y, Frank E, Alvarez FJ, Goulding M (2004) Pax6 and engrailed 1 regulate two distinct aspects of renshaw cell development. J Neurosci 24:1255-1264.

Scheibel MSA (1969) A structural analysis of spinal interneurons and renshaw cells. In: The interneuron (Brazier MAB, ed), pp 159-208. Berkeley, CA: University of California.

Sillar KT, Simmers AJ (1994) Electrical coupling and intrinsic neuronal oscillations in Rana temporaria spinal cord. Eur J Morphol 32:293-298.

Taccola G, Nistri A (2004) Low micromolar concentrations of 4-aminopyridine facilitate fictive locomotion expressed by the rat spinal cord in vitro. Neuroscience 126:511-520.

Tanabe Y, William C, Jessell TM (1998) Specification of motor neuron identity by the MNR2 homeodomain protein. Cell 95:67-80.

Tegner J, Hellgren-Kotaleski J, Lansner A, Grillner S (1997) Low-voltageactivated calcium channels in the lamprey locomotor network: simulation and experiment. J Neurophysiol 77:1795-1812.

Thaler J, Harrison K, Sharma K, Lettieri K, Kehrl J, Pfaff SL (1999) Active suppression of interneuron programs within developing motor neurons revealed by analysis of homeodomain factor HB9. Neuron 23:675-687.

Todd AJ, Hughes DI, Polgar E, Nagy GG, Mackie M, Ottersen OP, Maxwell DJ (2003) The expression of vesicular glutamate transporters VGLUT1 and VGLUT2 in neurochemically defined axonal populations in the rat spinal cord with emphasis on the dorsal horn. Eur J Neurosci 17:13-27.

Vosshall LB, Wong AM, Axel R (2000) An olfactory sensory map in the fly brain. Cell 102:147-159.

Vult von Steyern F, Martinov V, Rabben I, Nja A, de Lapeyriere O, Lomo T (1999) The homeodomain transcription factors Islet 1 and HB9 are expressed in adult alpha and gamma motoneurons identified by selective retrograde tracing. Eur J Neurosci 11:2093-2102.

Wichterle H, Lieberam I, Porter JA, Jessell TM (2002) Directed differentiation of embryonic stem cells into motor neurons. Cell 110:385-397.

Wilson JM, Brownstone RM (2004) Membrane potential oscillations in GFP postitive lamina VIII interneurons in the Hb9:eGFP mouse spinal cord. Soc Neurosci Abstr 30:883.13.

Wilson JM, Lieberam I, Jessell TM, Brownstone RM (2003) Electrophysiologi$\mathrm{cal}$ and morphological properties of spinal interneurons involved in locomotion in the Hb9-GFP mouse spinal cord. Soc Neurosci Abst 29:277.14. 